\title{
A emergência de metáforas multimodais: análise da metaforização e da compressão no debate político-eleitoral
}

\author{
Maíra Avelar Miranda * \\ Paulo Henrique Aguiar Mendes **
}

\begin{abstract}
Resumo
Neste artigo, pretendemos analisar a emergência das metáforas multimodais em interações face a face no debate político-eleitoral, levando em consideração duas variáveis: a verbal - que pertence à modalidade auditiva - e a gestual - que pertence à modalidade visual. Partimos da hipótese de que, quanto mais entrincheirada a expressão metafórica está em nosso sistema conceitual, mais difícil é reconhecer essa expressão como sendo metafórica. Por outro lado, quanto menos entrincheirada a expressão está em nosso sistema conceitual, mais fácil é reconhecê-la como uma expressão metafórica. Além disso, hipotetizamos que a veiculação de metáforas menos entrincheiradas funciona como um mecanismo de compressão da argumentação desenvolvida no turno de fala. A fim de demonstrar a emergência das metáforas nas modalidades acima citadas, bem como a relação entre essas modalidades, selecionamos cenas provenientes de uma réplica da candidata Dilma Rousseff, de um debate presidencial de segundo turno exibido pela Rede Record. Os resultados de análise corroboram as nossas hipóteses de trabalho e, além disso, tornam possível demonstrar como as variáveis verbais e gestuais podem interagir, a fim de gerar metáforas multimodais.

Palavras-chave: Metáforas multimodais. Metaforicidade. Compressão. Debate político-eleitoral.
\end{abstract}

\section{Introdução}

Neste artigo, pretendemos analisar a emergência das metáforas multimodais em interações face a face pertencentes ao gênero discursivo "debate políticoeleitoral", levando em consideração duas variáveis: a verbal - que pertence à modalidade auditiva - e a gestual - que pertence à modalidade visual. Tomando

* Professora adjunta da Universidade Estadual do Sudoeste da Bahia (UESB).

** Universidade Federal de Ouro Preto - UFOP 
como base a teoria da mente corporificada, bem como uma visão experiencialista da linguagem, selecionamos as seguintes categorias para orientarem a nossa análise: a metaforicidade multimodal em compostos verbogestuais, a compressão na argumentação e, finalmente, os efeitos perlocucionais. Considerando todas essas categorias, pretendemos realizar uma análise da emergência das metáforas no discurso da candidata Dilma Rousseff, do PT. Selecionamos, então, uma réplica formulada pela candidata. Após realizarmos as análises, pretendemos demonstrar como as variáveis verbais e gestuais podem interagir, a fim de gerar metáforas multimodais, que podem ser mais ou menos convencionais, dependendo do contexto de emergência delas.

\section{As abordagens corporificada e experiencialista}

Tal como anunciado anteriormente, as abordagens corporificada e experiencialista constituirão a base teórica que orientará este trabalho. A abordagem corporificada - tal como a abordagem experiencialista - parte do questionamento de uma longa tradição científica, filosófica e mesmo do senso comum que dicotomiza a questão "corpo x mente". Essa tradição é nomeada por Johnson (2007) de teoria representacional da mente. De acordo com a abordagem corporificada, em vez de considerar os processos cognitivos como puramente abstratos ou como padrões de reconhecimento separados das emoções e das ações motoras no mundo, tais processos entrelaçam-se com os ambientes materiais, sociais e culturais em que o corpo está imerso:

Usando o termo corporificada queremos chamar a atenção para dois pontos: primeiro, que a cognição depende de tipos de experiência decorrentes de se ter um corpo com várias capacidades sensório-motoras, e segundo, que essas capacidades sensóriomotoras individuais estão, elas mesmas, embutidas em um contexto biológico, psicológico e cultural mais abrangente. Utilizando o termo ação queremos enfatizar novamente que os processos sensoriais e motores - a percepção e a ação - são fundamentalmente inseparáveis na cognição vivida. De fato, os dois não estão apenas ligados contingencialmente nos indivíduos: eles também evoluíram juntos. ${ }^{1}$ (VARELLA; THOMPSON; ROSCH, 2003, p. 177, grifos dos autores).

1 Substituímos o termo "incorporada", em destaque, por "corporificada", pois achamos que o segundo termo se adequa com maior precisão à palavra inglesa "embodied". Essa substituição também foi feita nas traduções em que consta o termo "incorporação" - substituído por "corporificação". 
A partir das considerações acima, é possível inferir que as estruturas de processamento cognitivo não estão limitadas aos processos neuronais no/do cérebro, pois a abordagem corporificada estabelece que os processos cognitivos emergem de interações sensório-motoras contínuas entre cérebro, corpo e ambiente. Assim, é possível constatar que, ao contrário do que estabelecem as abordagens representacionalistas - que, no âmbito das Ciências Cognitivas, podem ser representadas pelas abordagens cognitivista e conexionista -, a abordagem da ação corporificada não concebe os pensamentos - ou os processos mentais em geral - como entidades trancafiadas na mente, tentando desesperadamente fazer contato com o mundo exterior: ao contrário, pensamentos seriam formas de ação e interação. Eles seriam, então, "no" e "do" mundo, em vez de serem "sobre" o mundo, pois são processos de experiência (JOHNSON, 2007). Consequentemente, a abordagem corporificada propõe um distanciamento do senso comum, para o qual a "representação" é compreendida em sentido estrito, como a re(a)presentação de um mundo previamente dado.

Do ponto de vista de sua aplicabilidade, a abordagem corporificada, partindo do princípio de que o corpo, o cérebro e o ambiente importam nos estudos cognitivos, conta com diversos teóricos em domínios de pesquisa que vão desde a neurobiologia e a linguística até a robótica e a filosofia. Isso resulta numa abordagem teórica ampla e multidisciplinar. A relação de continuidade entre corpo e mente, bem como a abordagem experiencialista servem como pano de fundo para as discussões que desenvolveremos sobre como se dá a emergência das metáforas, situadas numa prática sociocultural específica - o debate político-eleitoral -, que possui especificidades. O foco de nossa análise é a emergência de metáforas multimodais no debate. Portanto, questões relativas aos mapeamentos metafóricos, tanto no domínio verbal quanto no domínio gestual, serão amplamente discutidas em nossas análises. Antes, porém, de apresentarmos os dados, apresentaremos a abordagem experiencialista, outra abordagem-chave deste trabalho, do ponto de vista teórico.

No que diz respeito à abordagem experiencialista - ou mito experiencialista -, ela surgiu como uma tentativa de fazer frente aos mitos objetivista e subjetivista que, segundo Lakoff e Johnson (1980), dominam a maneira de pensar ocidental. Os autores questionam esses mitos, argumentando que ambos ignoram uma maneira de compreender o mundo por meio de nossas interações com ele: por um lado, o objetivismo ignora o fato de que a compreensão - e, portanto, a verdade - é 
relativa ao nosso sistema conceitual, que é culturalmente construído. Portanto, a compreensão não pode ser moldada por um sistema conceitual absoluto e neutro. O subjetivismo, por outro lado, ignora o fato de que a compreensão, mesmo a mais imaginativa, é construída nos termos de um sistema conceitual, que, por sua vez, é construído a partir do funcionamento bem-sucedido nos ambientes físico e cultural. Sendo assim, a metáfora, por exemplo, seria uma forma imaginativa de racionalidade.

Com base em evidências linguísticas - sobretudo relativas à metáfora conceptual -, Lakoff e Johnson (1980) argumentam que uma abordagem adequada para compreender nossa experiência, nossos pensamentos e nossa linguagem requer uma visão de que as questões do sentido e de como nós compreendemos nossa linguagem sejam moldadas pela nossa experiência. Sendo assim, ao contrário de isolar o homem do ambiente a fim de compreender aspectos externos e internos, no mito experiencialista, a compreensão emerge da interação; da negociação constante com o ambiente e com outros homens. Segundo Lakoff e Johnson (1980), a natureza dos nossos corpos interage com o ambiente e impõe uma estrutura à nossa experiência: experiências recorrentes levam à formação de categorias, que são Gestalten experienciais. Essas Gestalten, então, fornecem coerência à nossa experiência.

Segundo Lakoff e Johnson (1980), a proposta experiencialista fornece mais do que uma síntese entre objetivismo e subjetivismo: ela fornece uma perspectiva mais ampla a algumas das mais importantes áreas relativas à nossa experienciação da vida cotidiana. Uma dessas áreas é a Política, domínio ao qual pertence o nosso objeto de estudo:

as ideologias políticas e econômicas são enquadradas [framed] em termos metafóricos. Como todas as outras metáforas, as metáforas políticas e econômicas podem esconder aspectos da realidade. Mas na área da política e da economia as metáforas importam mais, pois elas direcionam nossas vidas. (LAKOFF; JOHNSON, 1980, p. 236).

Pretendemos analisar como as metáforas emergem no discurso políticoeleitoral, ecoando determinadas visões de mundo, moldando e sendo moldadas pela experiência dos sujeitos envolvidos no debate político. 


\section{A cognição nas interações: metaforicidade e compressão da argumentação}

Assumimos como desafio, neste trabalho, demonstrar como os fatores socioculturais moldam a nossa cognição. Estendendo ao âmbito cognitivo a questão de o homem e o ambiente se moldarem reciprocamente:

O ponto é que não só o corpo molda a mente corporificada, mas que as experiências do corpo-no-mundo também moldam a mente corporificada. Mas os mundos experienciais com os quais interagimos são mais do que simplesmente físicos; nós nascemos inseridos em meios sociais e culturais que transcendem nossos corpos individuais [situados] no tempo (...). A linguagem é outra porção do meio sócio-cultural dentro do qual existimos. É possível investigarmos como os fatores sócio-culturais (tais como a linguagem dentro da qual nascemos) moldam a nossa cognição? (ROHRER, 2007, p. 343 - tradução nossa). ${ }^{2}$

Nosso foco recai, sobretudo, em como interações face a face que ocorrem no debate político-eleitoral moldam e são moldadas pela cognição. No caso deste trabalho, o estudo das interações face a face demonstra que o processamento cognitivo, em geral - e o processamento metafórico, em particular - ocorrem por meio da ativação de mapeamentos online. Isso significa que esses mapeamentos são moldados pela interação, podendo ser modificados e reformulados no curso das interações, ao mesmo tempo em que moldam e direcionam a interação: levando-se em conta a estrutura do debate, a pergunta de um determinado candidato molda a resposta do seu oponente, sendo que o mesmo ocorre com as réplicas e tréplicas. Desse modo, os mecanismos cognitivos ativados - as metáforas e gestos utilizados, por exemplo - moldam e são moldados pela interação.

Nesse sentido, o conceito de Metaforicidade parece-nos bastante útil para abordar a emergência de metáforas nas interações, uma vez que a Metaforicidade pode desencadear elaborações metafóricas em várias modalidades e de maneira sucessiva no tempo. Sendo assim, em vez de se falar em Metáfora Conceptual

2 The point is not just that the body shapes the embodied mind, but that the experiences of the bodyin-the-world also shape the embodied mind. But the experiential worlds with which we interact are more than simply physical; we are born into social and cultural milieus which transcend our individual bodies in time (...). Language is another part of the socio-cultural milieu within which we exist. Can we investigate how socio-cultural factors (such as the language into which we are born) shape our cognition? 
como um princípio cognitivo estático, aborda-se a Metaforicidade como um princípio cognitivo geral, em que os mapeamentos metafóricos podem ser processados online. Dessa forma, a análise dos contextos sintático, semântico, prosódico e corporal revela que a Metaforicidade é uma propriedade dinâmica dos itens linguísticos, que pode estar mais ou menos em primeiro plano e, consequentemente, receber mais ou menos atenção focalizada. Dessa forma, a metaforicidade pode ser analisada como sendo uma forma dinâmica de cognição corporificada, ou seja, o processo cognitivo de entender uma coisa em termos de outra, tal como proposto pela Teoria da Metáfora Conceptual. Portanto, a emergência das metáforas nas enunciações em curso é gradativa, e não estática. Essa gradatividade da elaboração das expressões metafóricas pode ser descrita de maneira metafórica:

Em outros termos, é possível dizer que, neste momento, a metáfora estava dormindo; apenas como o falante está avançando, ele está construindo suas elaborações em palavras e gestos nesta expressão metafórica adormecida, usando-a, então, como fonte. Fazendo isso, ele deixa claro que metaforicidade se torna sucessivamente mais ativa, na medida em que o falante avança com o seu argumento, de modo que podemos falar, então, em metáforas acordadas [waking metaphors] (MÜLLER; CIENKI, 2009, p. 216 - tradução nossa). ${ }^{3}$

Em outras palavras, quanto mais a atenção do falante é direcionada à expressão metafórica, mais alto é o grau de ativação da Metaforicidade (CIENKI; MÜLLER, 2008). E o que direcionaria, em maior ou menor grau, a atenção do ouvinte? Acreditamos que, quanto mais alto o grau de convencionalidade das metáforas, mais entrincheiradas elas estão no sistema conceptual do falante e do ouvinte e, consequentemente, menor atenção é direcionada a elas. Por outro lado, quanto mais alto o grau de novidade das metáforas, menos entrincheiradas elas estariam no sistema conceptual do falante e do ouvinte e, consequentemente, maior atenção seria direcionada a elas. Além disso, hipotetizamos que, no debate político-eleitoral, as metáforas funcionam como mecanismos de compressão da argumentação expressa

3 Put differently, at this moment the metaphor was sleeping; only as the speaker is moving on is he building his elaborations in words and gestures on this sleeping metaphoric expression, thus using it as source. Doing this makes clear that metaphoricity becomes successively more active, as he moves along with his argument, such that we may now speak of waking metaphors. 
no turno de fala: as metáforas mais convencionais expressariam um baixo grau de compressão, enquanto as menos convencionais expressariam um alto grau de compressão.

A fim de explicitarmos melhor essa hipótese, abordaremos o conceito de compressão (FAUCONNIER; TURNER, 2002, p. 119), como também o funcionamento da compressão nas interações (HOUGAARD; RASMUSSEN, 2008). O conceito de compressão e a sua contraparte, a descompressão, foram desenvolvidos por Fauconnier e Turner (2002). Segundo os autores, um dos benefícios centrais da Integração Conceitual - doravante, IC - é a sua capacidade de fornecer compressões, para a escala humana, de redes difusas de eventos, de modo que determinadas relações conceituais, tais como tempo, espaço, causa-efeito, identidade, analogia e mudança, aparecem repetidas vezes na compressão obtida por meio da IC. Essas relações de suma importância conceitual são chamadas de "relações vitais". A compressão maximiza e intensifica essas relações vitais, sendo que a IC pode realizar compressões maciças e expressá-las de forma simples.

No caso do discurso político e, mais especificamente, da argumentação desenvolvida no discurso político-eleitoral, a exemplo do debate eleitoral, que ora nos interessa, destacamos a importância do processo de compressão promovido pela IC, no sentido de que questões políticas extremamente complexas (relativas à administração pública, às condições de vida, trabalho, economia, etc.) teriam que ser ostensivamente explicadas, o que não impediria de serem dissimuladas, técnica e didaticamente, para um público extremamente heterogêneo, demandando grande quantidade de tempo, se elas não pudessem ser objeto do processo de compressão, através do qual podem ser mapeadas/projetadas metaforicamente através de domínios mais primitivos da nossa experiência, tornando-se, assim, mais compreensíveis - mas também dissimuláveis - num intervalo menor de tempo, ou seja, mais rapidamente. Nesse sentido, o processo de compressão por meio da IC satisfaz cognitiva e pragmaticamente as condições de processamento do discurso político eleitoral e, por extensão, do debate eleitoral, submetido a regras comunicacionais que restringem o tempo e a forma de argumentação dos candidatos. Assim, acreditamos que o processamento discursivo do debate eleitoral se faz estrategicamente através de metáforas multimodais que comprimem a argumentação, produzindo Gestalten experienciais, de modo a torná-la mais eficiente, em termos interacionais. 
A partir das considerações teóricas feitas ao longo deste trabalho, discutiremos modelos de análise que possam contemplar a complexidade das trocas comunicativas que ocorrem no debate político-eleitoral, como também elencaremos categorias que possam orientar a análise de metáforas multimodais em nosso corpus de análise.

\section{Em busca de um modelo de análise: o modelo da semiótica cognitiva}

Desenvolvendo e problematizando a formulação da Teoria da Integração Conceitual, Brandt e Brandt (2005) propõem que a noção de espaço-base não seria um dado a priori, mas ontologicamente construída, tendo como base a semiose. Sendo assim, o espaço-base seria discursivo, pois é construído a partir de "o ato de dizer e aquilo que é dito" - é importante ressaltar que as duas operações são observadas como sendo distintas uma da outra e são, então, representadas separadamente. Portanto, "a semiose (a situação em que enunciados ou outras trocas de sinais ocorrem) é a base para a construção de espaços" (BRANDT; BRANDT, 2005, p. 19 - tradução nossa). ${ }^{4}$ Em suma:

Um espaço (base) semiótico é um espaço mental em que o [sujeito] cognoscente representa a situação atual de cognoscer. $\mathrm{Ou}$ é uma cena de comunicação, envolvendo as pessoas que participam na construção de significado compartilhado através da rede semântica considerada, ou uma cena de reflexão envolvendo o sujeito "refletor" e a situação em que a reflexão tem lugar, tal como representada pelo sujeito. Assim, é assumido como sendo o caso, fenomenologicamente, que quando as pessoas se comunicam, elas representam a situação de comunicação, e essa representação compartilhada é um pré-requisito para a construção de sentido (BRANDT; BRANDT, 2005, p. 20, tradução nossa). ${ }^{5}$

4 The semiosis (the situation in which utterances or other exchanges of signs occur) is the base for space building.

5 A semiotic (base) space is a mental space in which the cognizer represents the present situation of cognizing. It is either a scene of communication, involving the persons participating in shared meaning construction through the semantic network considered, or a scene of reflection involving the reflecting subject and the situation in which the reflection takes place, as represented by the subject. It is thus assumed to be the case, phenomenologically, that when people communicate, they represent the situation of communication, and this shared representation is a prerequisite for meaning construction. 
Como podemos perceber, para Brandt e Brandt (2005), o processo de cognoscer tem o sujeito cognoscente como elemento central, assim como o ato de comunicação é decorrente das trocas comunicativas entre sujeitos. Dessa forma, a cognição decorre do ato de cognoscer, realizado por um ou mais sujeitos, e é construída pela comunicação entre sujeitos e pelo contexto situacional. Sendo assim, no modelo da Semiótica Cognitiva, é proposta uma arquitetura de espaços projetados pelos sujeitos em suas interações. Nessa perspectiva, a noção de espaço pode ser traduzida pela projeção de esquemas/cenários cognitivos construídos pelos sujeitos em suas interações.

Na versão apresentada por Brandt e Brandt (2005) e adaptada por nós (2013), a arquitetura dos espaços é composta: (i) pelo espaço-base semiótico (o qual é desdobrado em três esferas: a da semiose propriamente dita, como instância de realização de atos de linguagem pelos interlocutores; a da situação de comunicação em que se encontram os participantes da interação; e a do mundo fenomenológico mais amplo, acessível à nossa experiência vivida); (ii) pelos espaços de entrada, chamados de espaços de apresentação (instância textual) - desdobrados em duas dimensões: a dos recursos gestuais e prosódicos e a dos significados linguísticos - e de referência (instância objeto); (iii) pelo espaço virtual (blend), projetado a partir da seleção de elementos dos cenários (frames) dos dois últimos espaços; e (iv) pelo espaço de relevância, o qual orienta o sentido emergente do espaço virtual.

Em conclusão, o modelo da Semiótica Cognitiva torna possível analisar como nós processamos cognitivamente mesclas (blends). Segundo Brandt e Brandt (2005), no Espaço Semiótico (ES), as integrações são construídas online e são sensíveis ao contexto, tanto no que diz respeito à construção das entradas (inputs) quanto no que diz respeito à relevância semântica e pragmática de se integrar as entradas (inputs) em questão. Na seção seguinte, aplicaremos o modelo descrito ao nosso corpus de análise, com vistas a contemplarmos a natureza multimodal e interativa desse corpus. 


\section{Seleção do corpus e descrição dos procedimentos de análise}

Analisaremos uma réplica da candidata Dilma Rousseff, que pertence a uma sequência do debate de segundo turno transmitido pela Rede Record no dia 25/10/2010. É importante salientar que o segundo turno das eleições foi marcado pelo surgimento de diversas questões polêmicas, tanto nos debates quanto fora deles: houve uma larga difusão de informações, especialmente via internet e via revistas de grande circulação, que visavam a desqualificar os candidatos. Abaixo, temos um exemplo bem emblemático disso:
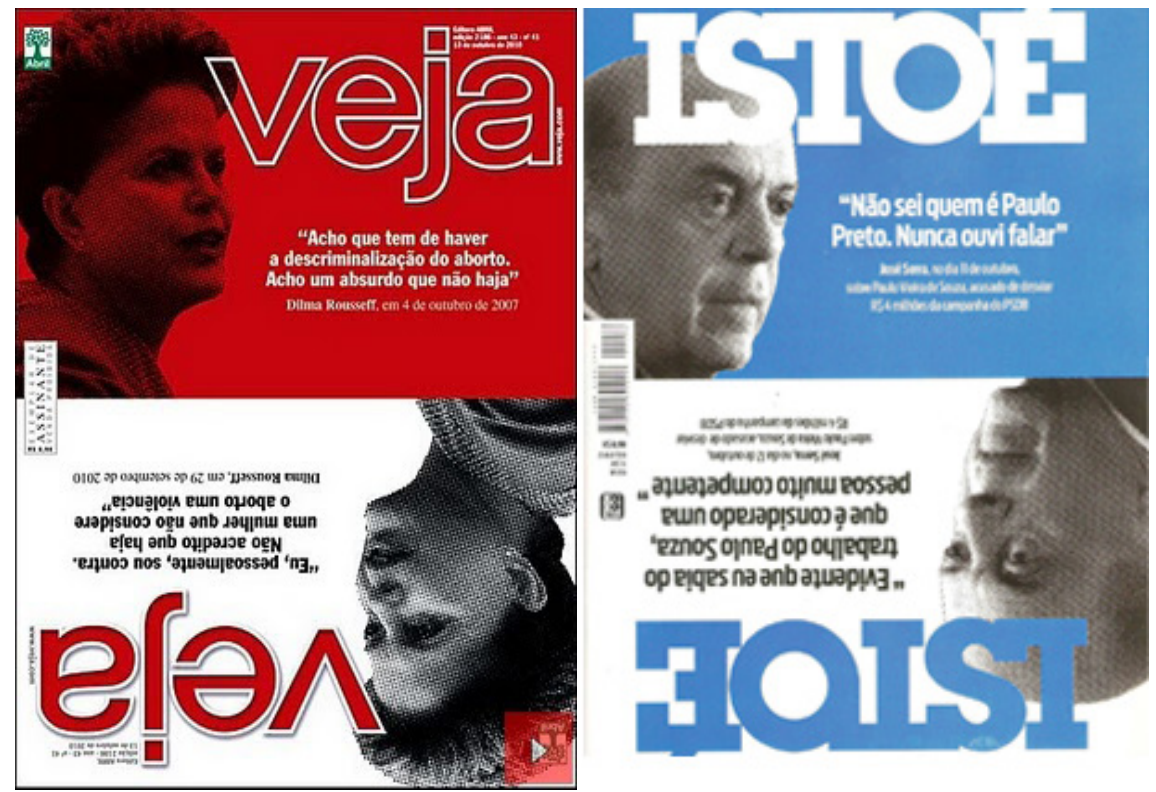

FIGURA 1 - Capas das revistas Veja e IstoÉ - Fontes: Sites das Revistas Veja e IstoÉ.

Como é possível observar, os veículos impressos se valeram da seguinte metáfora: "MENTIR É TER DUAS CARAS", bastante recorrente também nos debates. A capa da revista Veja, referente à edição de 11 de outubro de 2010 - veiculada um dia após o debate da Band -, faz uma crítica explícita ao posicionamento contraditório de Dilma em relação ao aborto. Em resposta, a capa da revista IstoÉ, referente à edição de 16 de outubro de 2010, nove dias antes do Debate da Record, faz uma crítica explícita ao posicionamento contraditório de Serra em relação ao ex-assessor da Casa Civil paulista, Paulo Vieira de Souza. 
Na sequência escolhida para análise, especificamente, Dilma faz uma pergunta sobre emprego, e a resposta de Serra, a réplica de Dilma e a tréplica de Serra abordam o tema da privatização do pré-sal, que pode ser considerado como o tema mais recorrente dos debates de segundo turno, atrelado à comparação entre os governos FHC e Lula - como pode ser ilustrado e comprovado no trecho.

Optamos por analisar as metáforas tendo em vista a integração de dois níveis: o verbal e o gestual. A fim de realizarmos a descrição do nível verbal, sublinhamos os trechos onde foram identificadas ocorrências verbais de metáforas e procuramos contextualizá-los, trazendo algumas frases que os antecediam e os sucediam, bem como a transcrição completa dos trechos analisados (Anexo A). Em relação à análise do nível gestual, tal como apontado por diversos pesquisadores de gestos (referenciados em obras como Metaphor and Gesture e Multimodal Metaphor), estabelecer uma metodologia adequada ao estudo dos gestos constitui um desafio, sobretudo em casos de análises como a proposta neste trabalho, que reúne informações pertencentes a diferentes modalidades. A fim de realizarmos a análise dos gestos, optamos por fotografar o Curso dos gestos (KENDON, 2004) que veiculam metáforas, acompanhados da fala, bem como dos gestos que acompanham as frases metafóricas. As análises gestuais a que tivemos acesso mostram desenhos dos gestos feitos pelos interlocutores. No entanto, achamos mais preciso e mais ilustrativo fotografarmos o corpus. Além de sublinharmos os trechos em que são veiculadas as metáforas verbais, optamos por destacar com negrito o momento da fala em que a excursão gestual acontece, fotografar o Curso e descrever a excursão gestual como um todo, focalizando três aspectos:

- a direção do gesto: ascendente, descendente, para a esquerda, para a direita etc;

- a configuração das palmas das mãos: para cima, para baixo, em soco etc;

- outros aspectos relevantes, que não incluem apenas as mãos: posição do corpo, expressões faciais etc, quando julgamos relevante descrever.

A escolha pela focalização feita no curso do gesto pode ser assim justificada: "Enquanto o gesto prototípico passa por três fases - a preparação, o curso e a retração - é a fase do curso que é considerada como a que constitui minimamente 
um gesto" (CIENKI, 2008, p. 6 - tradução nossa). ${ }^{6}$ A seguir, descreveremos as categorias que orientarão as nossas análises.

No âmbito das metáforas multimodais, é possível descrever duas ocorrênciaspadrão da relação entre gestos e fala (MÜLLER; CIENKI, 2009, p. 307):

1 - É possível encontrar a mesma fonte e o mesmo alvo em modalidades diferentes. Nesses casos, o gesto corporifica o domínio-fonte da expressão metafórica verbal, indicando que a metaforicidade dessa expressão foi ativada ou estava no primeiro plano da atenção do falante.

2 - É possível, também, encontrar fontes diferentes e o mesmo alvo, em modalidades diferentes. Nesses casos, encontramos uma expressão metafórica gestual, com um alvo que é verbalizado de uma forma não metafórica.

\section{Análise dos dados}

Analisaremos, a seguir, um trecho correspondente a um fragmento da réplica, que é constitutiva da sequência de turnos típica do gênero debate, caracterizada por: Pergunta-Resposta--Réplica-Tréplica, pertencente, no nosso caso específico, ao Debate da Record. Por questões de economia de espaço/tempo, reproduziremos a seguir, no corpo do texto, apenas um excerto da réplica de Dilma, em que a presença de metáforas se destaca.

Dilma: (...) e é bom que você saiba que a grande maioria dos países agiu dessa forma: descobriu reserva do tamanho do pré-sal. Porque a diferença entre você descobrir uma mina de ouro (1) e descobrir uma minazinha pequenininha (2). Então o quê que eu digo para vocês? Eu digo que eles tão querendo privatizar o filé mignon (3). A carne de pescoço (4) era o que existia antes. Agora tão

6 While a prototypical gesture passes through three phases - the preparation, stroke, and retraction - it is the stroke phase which is considered to minimally constitute a gesture. 


\section{querendo entregar o filé mignon do país (5).}

(1)

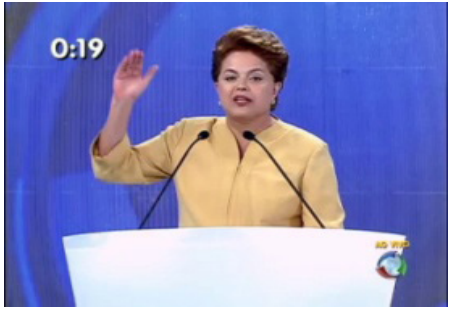

Gesto ascendente, mão direita, lado direito do corpo.

(3)

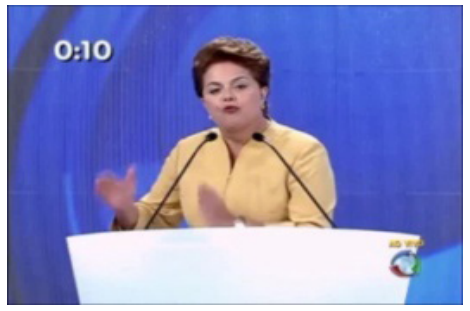

Gesto lateral, ambas as mãos, palmas paralelas uma à outra.
(2)

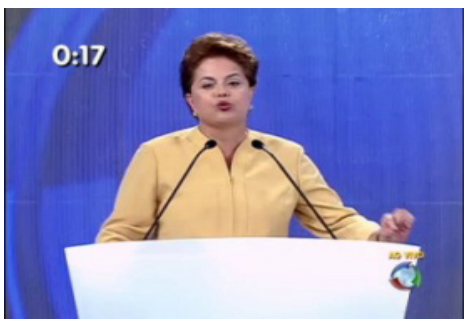

Gesto descendente, mão esquerda, lado esquerdo do corpo.

(4)

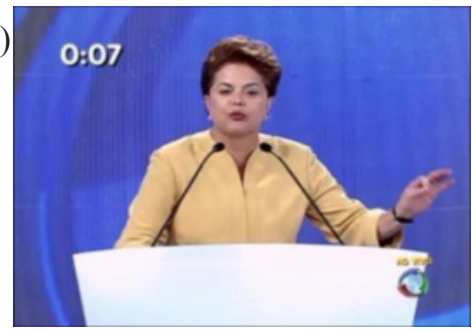

Gesto lateral, mão esquerda, lado esquerdo do corpo, polegar e indicador fechando-se em círculo.

(5)

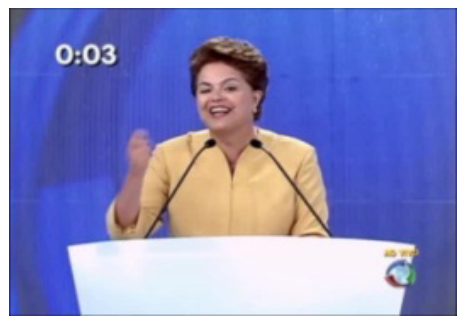

Gesto descendente, mão direita fechada, lado direito do corpo.

Fazendo um breve histórico da temática em questão, o processo de privatizações está associado a uma doutrina liberal de desregulamentação das instituições e de minimização do papel do Estado ou do setor público na economia. Na América Latina, a doutrina e a política de privatizações tiveram seu apogeu nos anos 
noventa, como estratégia tanto discursiva quanto acional voltada para supostamente produzir o crescimento econômico dos países da região. Pesquisas de opinião, realizadas sobretudo a partir do ano 2000, passaram a apontar para uma insatisfação grande da sociedade civil nos países da América Latina em relação ao processo de privatizações. No Brasil, o jornalista Elio Gaspari cunhou, inclusive, o termo "privataria", como forma pejorativa de designar esse processo no caso específico brasileiro, o que, de certo modo, ganhou visibilidade política nas eleições.

Como tema de campanha, as privatizações foram objeto de polêmica entre os dois principais candidatos, Dilma (PT) e Serra (PSDB), sendo que a estratégia de base da candidata do governo petista foi a comparação entre o governo anterior (FHC) e o governo então vigente (Lula), criticando as privatizações do governo anterior e elogiando a valorização do patrimônio público do governo vigente. A candidatura governista se ancora em uma memória discursiva nacionalista, em uma herança getulista do 'petróleo é nosso' e em uma história republicana de construção do Estado.

Assim, na réplica recortada acima, Dilma refuta as críticas feitas por Serra ao fato de o PT ter feito privatizações na Petrobras. A candidata encadeia uma sequência de enunciados contra o partido de seu adversário, cujo principal ato ilocucional corresponde à predição de pretender privatizar o pré-sal. Depois de dizer que Serra é mal-informado e de defender o regime de partilha da exploração do Petróleo com predomínio do controle pela Petrobrás, Dilma, na primeira parte do exemplo apresentado acima - gestos 1 e 2 -, utiliza a metáfora "RESERVAS DE PETRÓLEO São MINAS DE OURO", que é apresentada dentro de uma oposição: descoberta atual > mão direita no alto, coocorrendo com "mina de ouro" x descoberta anterior > mão esquerda embaixo, coocorrendo com uma variação, no diminutivo, da metáfora: “minazinha pequenininha”. Além da representação verbogestual representar oposição, ela também expressa uma relação temporal, que pode ser formulada da seguinte maneira: "O FUTURO É PARA FRENTE" - no caso, para a direita - e "O PASSADO É PARA TRÁS" - no caso, para a esquerda. Ainda sobre o exemplo fornecido, é possível explorar a questão dos eixos horizontal e vertical, em que o gesto realizado com a mão direita, do meio para cima, representa crescimento (CALBRIS, 2008), enquanto o gesto realizado com a mão esquerda, do meio para baixo, representa diminuição.

Já na segunda parte do exemplo - gestos de 3 a 5 -, Dilma utiliza metáforas que remetem a elementos do universo popular, recorrendo a uma memória discursiva 
relacionada ao presidente Lula, que frequentemente se utilizava de situações cotidianas para veicular metáforas mais próximas do imaginário popular. Nesse caso, Dilma faz referência a partes/cortes de carne animal tradicionalmente conhecidos e consumidos para metaforizar a dicotomia "passado x futuro", utilizando o filémignon, parte nobre do boi, para sinalizar o presente, e a carne de pescoço, carne barata, para sinalizar o passado. É relevante assinalar que ela encena ambas as metáforas com as mãos: primeiramente, ela encena o filé, que é representado como um objeto grande, e, posteriormente, ela encena a carne de pescoço, que é representada como um objeto pequeno. A última metáfora verbogestual articula a frase - "Agora estão querendo entregar o filé-mignon do país" - à encenação, com a mão direita, do gesto de entregar (gesto 5), comprimindo a argumentação desenvolvida por Dilma no turno em questão. Temos aqui um processo fortemente metafórico de compressão, a partir de algumas relações vitais: analogia [petróleo $=$ carne $]$, espaço/tempo $[$ direita $=$ futuro $\mathrm{x}$ esquerda $=$ passado, alto $=$ mina grande $\mathrm{x}$ baixo $=$ mina pequena], causa-efeito [governo Serra $\rightarrow$ privatização do pré-sal], etc.

Aplicando o modelo da Semiótica Cognitiva à réplica de Dilma, teríamos o seguinte resultado: a cena enunciativa colocada em funcionamento é "filtrada socioculturalmente" pelo Domínio Discursivo político-eleitoral, em que, do ponto de vista da Relevância Argumentativa, os candidatos utilizam estratégias para minar a credibilidade do adversário, desqualificando-o. Na situação comunicativa em questão, ou seja, no debate político-eleitoral, Dilma fez uso do histórico privatista do PSDB, partido de Serra, abordando o tema da privatização do pré-sal, principal tema abordado no debate. Lançando mão de uma estratégia de antecipar discursivamente as ações do adversário num futuro governo, hipoteticamente vitorioso - repetindo a estratégia, utilizada na campanha do PT de 2006, de satanização das privatizações - a candidata do PT, em 2010, afirmou que os tucanos defendiam a privatização da Petrobras e do pré-sal, prevendo que o candidato adversário iria privatizar as reservas de petróleo.

Ao se referir ao pré-sal e às reservas de petróleo, Dilma os apresenta como "mina de ouro" e "filé-mignon". Por meio da utilização dessas metáforas, a candidata compara as reservas de petróleo descobertas anteriormente com o pré-sal, encenando gestualmente, em ambas as sequências comparativas, dois objetos que ocupam posições opostas no espaço, promovendo, assim, a distinção "passado" x "futuro". Ela também utiliza a metáfora verbogestual "entregar o filé- 
mignon do país", que corresponde a privatizar as reservas de petróleo. A predição e a consequente acusação das ações futuras do adversário resultam, de certo modo, num efeito demagógico que podemos chamar de "profecia eleitoral", que mobiliza a emoção do medo, ao mesmo tempo em que projeta uma imagem da candidata do governo como a grande protetora do patrimônio nacional. Essa aplicação do modelo descrita pode ser ilustrada da seguinte maneira:

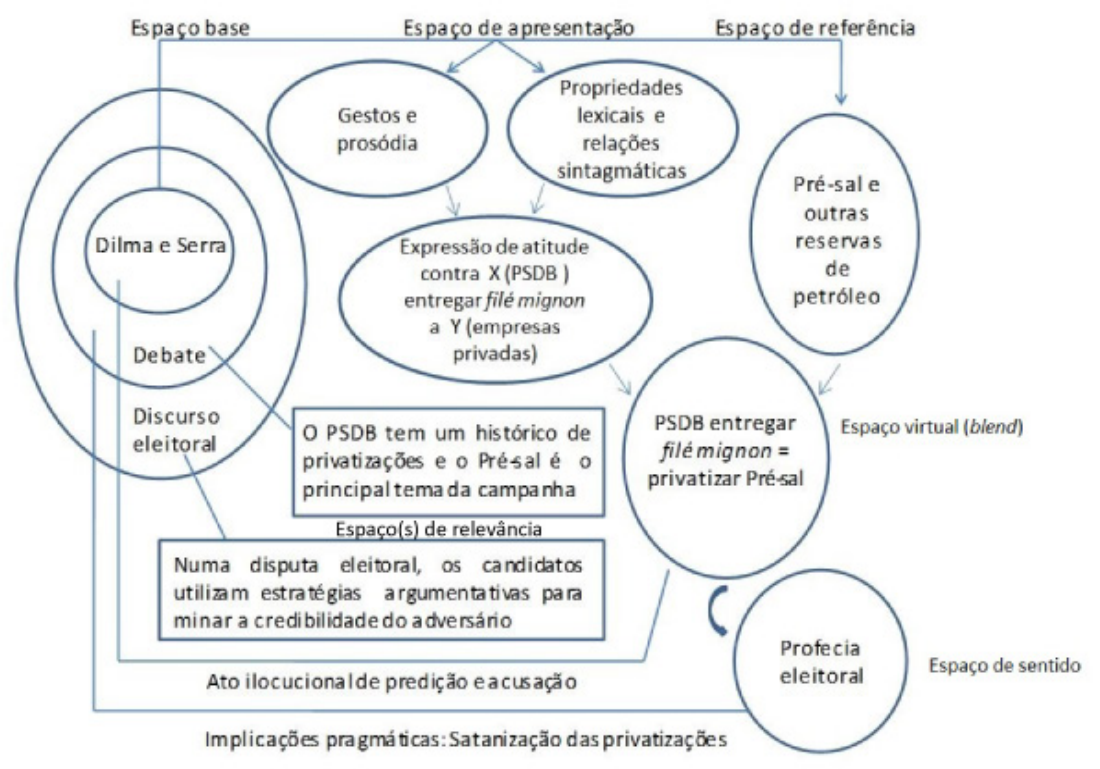

FIGURA 1 - Modelo semiótico adaptado, aplicado à réplica de Dilma Fonte: Elaborado pelos autores.

\section{Considerações finais}

Fundamentada em uma concepção experiencialista (LAKOFF; JOHNSON, 1980) e corporificada (JOHNSON, 2007; ROHRER, 2007) da linguagem, e amparada numa versão adaptada do modelo da Semiótica Cognitiva (BRANDT; BRANDT, 2005), a análise de metáforas multimodais emergentes no debate eleitoral nos permitiu atestar, ao menos nos exemplos de nossa amostra, que, por um lado, quanto mais convencionalizadas elas são, maior a dificuldade de 
reconhecer a natureza metafórica das expressões que as manifestam. Por outro lado, quanto menos convencionais elas são, maior a facilidade de reconhecer a natureza metafórica das expressões que as manifestam e, além disso, mais recursos gestuais tendem a ser utilizados para direcionar a atenção do ouvinte para o que está sendo dito, potencializando a geração de efeitos perlocucionais. Essa hipótese se relaciona a outra, também corroborada pelos dados aqui avaliados: a de que o uso dessas metáforas no discurso político-eleitoral e, mais especificamente, no debate eleitoral constitui, mais do que uma simples manifestação do fenômeno da compressão das relações vitais produzida pela integração conceitual, estratégias de compressão da própria argumentação dos candidatos, como busca de satisfazerem cognitiva e pragmaticamente as restrições típicas dessa situação de interação, com vistas a serem bem-sucedidos em seus projetos discursivos.

\title{
The emergence of multimodal metaphors: the analisis of the metaphorization and of the compression in the political-electoral debate
}

\begin{abstract}
In this paper, we intend to analyze the emergence of the multimodal metaphors in face to face interactions in the political-electoral debate, taking into consideration two variables: the verbal - pertaining to the aural modality - and the gestural - pertaining to the visual modality. Our hypothesis is that the more entrenched in our conceptual system the metaphoric expression is, the more difficult it is to recognize it as metaphoric. On the other hand, the less entrenched in our conceptual system the metaphoric expression is, the easier it is to recognize it as a metaphoric expression. Moreover, we hypothesized that the emergence of less entrenched metaphors works as a compression mechanism of the argumentation developed in the speeech turn. In order to demonstrate the emergence of the metaphors in the modalities listed above, as well as the relation between these modalities, we selected scenes coming from a replic formulated by the candidate Dilma Rousseff, from a second turn presidential debate broadcasted by Rede Record, a Brazilian TV channel. The analysis results support our research hypothesis and also allow us to demonstrate that the verbal and gestural variables can interact, generating multimodal metaphors.
\end{abstract}

Keywords: Multimodal metaphors. Metaphoricity. Compression. Turn-packing. Political-electoral debate. 
Referências

BRANDT, Line; BRANDT, Per Aage. Making sense of a Blend. Annual Review of Cognitive Linguistics, Amsterdam, v. 3, p. 216-249, 2005.

CALBRIS, Geneviève. From left to right...: coverbal gestures and their symbolic use of space. In: CIENKI, Alan; MÜLLER, Cornelia (Ed.). Metaphor and gesture. Amsterdam: John Benjamins, 2008. p. 27-54.

CIENKI, Alan. Image Schemas and Gestures. In: HAMPE, Beate; GRADY, Joseph E. (Ed.). From perception to meaning: Image Schemas in Cognitive Linguistics. Berlin, New York: Mouton de Gruyter, 2005. p. 421-442.

CIENKI, Alan. Why to study metaphor and gesture? In: CIENKI, Alan; MÜLLER, Cornelia (Ed.). Metaphor and gesture. Amsterdam: John Benjamins, 2008. p. 3-26. FAUCONNIER, Gilles; TURNER, Mark. The way we think: Conceptual blending and the mind's hidden complexities. New York: Basic Books, 2002.

HOUGAARD, Anders; RASMUSSEN. Gitte. Implications of cognitive metaphor and gesture studies for Ethnomethodology and Conversation Analysis and vice versa. In: CIENKI, Alan; MÜLLER, Cornelia. Metaphor and gesture. Amsterdam: John Benjamins, 2008. p. 265-273.

JOHNSON, Mark. The meaning of the body: aesthetics of human understanding. Chicago, London: The University of Chicago Press, 2007.

KENDON, Adam. Gesture: visible action as utterance. Cambridge: Cambridge University Press, 2004.

LAKOFF, George; JOHNSON, Mark. Metaphors we live by. Chicago, London: The University of Chicago Press, 2003. Original publicado em 1980.

MIRANDA, Maíra Avelar. A emergência de metáforas multimodais no discurso político-eleitoral: análise das variáveis verbais, prosódicas e gestuais em debates de segundo turno às eleições presidenciais de 2010. 2013. Tese (Doutorado em Linguística) - Pontifícia Universidade Católica de Minas Gerais, Belo Horizonte, 2013.

MÜLLER, Cornelia; CIENKI, Alan. Words, gestures, and beyond: Forms of multimodal metaphor in the use of spoken language In: FORCEVILLE, Charles J.; URIOS-APARISI, Eduardo (Ed.). Multimodal metaphors. Berlin, New York: Mouton de Gruyter, 2009. p. 297-328. 
ROHRER, Tim. The body in space: Embodiment, Experientialism and Linguistic Conceptualization. In: ZIEMKE, Tom; ZLATEV, Jordan; FRANK, Roslyn; DIRVEN, René (Ed.). Body, Language and Mind Berlin: Mouton de Gruyter, 2007a. v. 1, p. 339-378.

VAN DIJK, Teun A. Discurso político e cognição política. In: VAN DIJK, Teun A. Discurso e poder. São Paulo: Contexto, 2008. p. 197-230.

VARELA, Francisco J.; THOMPSON, Evan; ROSCH, Eleanor. Cognition as Embodied Action. In: THOMPSON, Evan; VARELA, Francisco J.; ROSCH, Eleanor. The embodied mind. Cambridge, MA: MIT Press, 2003. p. 172-179.

Anexo

Dilma: Olha, candidato Serra, você ficou caladinho quando mudaram o nome Petrobrax, substituindo o Brás de Brasil. Naquela época, chegaram ao cúmulo de tirar até a bandeira do Brasil, BR, lá do nome da Petrobras. Privatizar o pré-sal, candidato, é um absurdo e é isso que vocês propõem sim. O seu partido votou contra o modelo de partilha. O senhor não tem coragem de assumir a sua posição, e que fica falando que num se influencia pelos outros. Ora, então, o senhor tá no partido errado, porque seu partido vota contra a garantia de que a Petrobras será a exploradora do pré-sal. Aliás essa fala dele, da maioria dos blocos serem estrangeiros, ela é mentira. Por que que é mentira? Eu não estou dizendo que você mente: eu estou dizendo que você é muito mal-informado e a frase é mentirosa. Por quê? Porque, na maioria dos casos, há o controle pela Petrobras dos blocos. A questão não é essa. A questão é que, no modelo anterior, tudo ficava pra empresa privada estrangeira ou pra qualquer empresa. Agora não: agora, como é muito dinheiro e o recurso é muito grande, e é bom que você saiba que a grande maioria dos países agiu dessa forma: descobriu reserva do tamanho do pré-sal. Porque a diferença entre cê descobrir uma mina de ouro e descobrir uma minazinha pequenininha. Então o quê que eu digo para vocês? Eu digo que eles tão querendo privatizar o filé-mignon. A carne de pescoço era o que existia antes. Agora, tão querendo entregar o filé-mignon do país. 
